\title{
An Empirical Study of Application of Cultural Confidence to Translation Teaching in College English
}

\author{
Yiqin Zou $^{1} \&$ Xiao Huang ${ }^{2}$ \\ ${ }^{1}$ School of Foreign Studies, Jiangxi University of Engineering, Jiangxi, China \\ ${ }^{2}$ Jiangxi Tellhow Animation Vocational College, Nanchang, China \\ Correspondence: Yiqin Zou, School of Foreign Studies, Jiangxi University of Engineering, Xinyu, Jiangxi, China. \\ E-mail: zouyiqinmm@163.com
}

\author{
Received: February 13, $2021 \quad$ Accepted: March 15, $2021 \quad$ Online Published: March 24, 2021 \\ doi:10.5539/ijel.v11n3p19 URL: https://doi.org/10.5539/ijel.v11n3p19
}

\begin{abstract}
This paper presents the validity and credibility of the effect of translation teaching in College English (CE) interfered with comparative linguistic cultural knowledge between Chinese and English aiming at raising non-English majors' cultural confidence on translation competence. Based on empirical research, the details of our research include questionnaire, pre-test, teaching experiment, post-test and interview. The analysis of data of pre-test and post-test through SPSS 26.0 reveals that the translation competence of students in Experimental Class (EC) has been improved significantly after a semester's new translation teaching approach. Students hold positive attitudes to raising their cultural confidence in translation teaching by introducing linguistic cultural knowledge. Two implications, the improvement of discourse system combining the Eastern and Western culture and the positive effects of translation teaching in CE have been discussed. And three limitations, the time, the size, and importantly the abstract aspect of linguistic cultural knowledge itself on a comparative perspective of the study have been put forward at the end of this paper.
\end{abstract}

Keywords: translation teaching, College English, linguistic cultural knowledge, cultural confidence, translation competence

\section{Introduction}

Globalization has been deepened sharply with the development of science and technology. Mutual negotiation, mutual construction and mutual share have turn into a trend in current times. So, cultural exchanges and communications are increasing. Hence, translation plays a growing important role in the modern world. The growing concern of non-English college students' translation competence comes along with that. It is undeniable that translation teaching occupies a main part of College English (CE). So improving the efficiency of translation teaching in CE gains more attention among linguistic researchers. General Secretary Xi Jinping has put forward that carrying forward the education of socialist core values and enhancing cultural self-confidence is an important cultural strategic core of national governance (Han, 2019, p. 158). Cultural confidence is a nation or a country's full affirmation, the active practice of its own cultural value, and the firm confidence in the vitality of its culture (Shen, 2021, p. 33). Some studies show that the Chinese competences of Chinese college students are weak (Tu, 2009, p. 76; Tu, 2010, p. 5; Cu \& Yan, 2008, p. 227; Zou, 2016, p. 55). Given that, the researchers wonder that are students' attitudes toward raising their cultural confidence positive or negative? Will students' translation competence be improved after learning certain linguistic culture knowledge with the purpose of raising their cultural confidence? The study here aims at studying whether interfering translation teaching in $\mathrm{CE}$ with linguistic cultural knowledge both containing Chinese and English aiming at raising non-English students' cultural self-confidence can improve their translation competence or not. This research hopes to find a path to non-English majors to improve their translation competence in order to fit the current global atmosphere.

\section{Literature Review}

\subsection{Translation Competence and Translation Teaching}

Overseas, the most systematical and comprehensive study about translation competence is the study made by PACTE GROUP. The group has touched the translation competence field since 1997. So, here, we adopt the translation competence model established by the GROUP comprising six sub-competences components: 
bilingual sub-competence, extra-linguistic sub-competence, knowledge about translation, instrumental sub-competence, strategic and psycho-physiological competence (PACTE GROUP, 2009, pp. 208-209). Askari et al. (2018), Shehab et al. (2020), and Siregar et al. (2020) have studied how to improve students' translation competence or proficiency in translation teaching, which studied from the aspect of lingual sub-competence, extra-linguistic sub-competence and strategic sub-competence respectively. Suparman et al. (2013) and Lynda (2020) research translation teaching in the aspect of computer and multimodality, which stand at the pinpoint of instrument sub-competence. We can say that extra-linguistic sub-competence is not a highly frequent concern in translation teaching.

Domestically, Huang (1997), Mu (2006), Miao (2007), Wen (2004), Tong (2010) and Wang et al. (2020), etc. studied the field of translation competence. Huang (1997, p. 26) indicates grammar-translation competence and grammar-point-oriented translation exercises are common in textbooks of overseas and home. It is an indication of grammar-translation competence playing an important role in translation competence. Wen $(2004$, p. 1) summarizes translation competence containing linguistic/textual competence, strategic competence and self-evaluation competence. Miao (2007, p. 48) categorizes translation competence into cognitive competence, linguistic competence and communicative competence. Wang et al. (2020, p. 215) regard the transfer competence as the only one that can distinguish translation from other similar activities for the limited research time span. Huang (2020, p. 12) indicates the necessity of and existing problems in College English translation teaching, which points out that teachers also need to strengthen their (here referring to College students) understanding of cross-cultural knowledge. It can be concluded that the extra-linguistic knowledge is an ignorance in translation competence. So, this paper wants to study the effect of extra-linguistic knowledge in translation teaching on translation competence.

\subsection{Cultural Confidence and Translation Teaching}

$\mathrm{Lu}(2019$, p. 1869) indicates that the need of cultivation of cultural confidence in foreign literature course.

“...English and American Literature should combine teaching of English and American Literature with cultivation of students' confidence of Chinese literature, so a comparative analysis between English and American literature and Chinese literature should be employed in Chinese higher education institutions because cultural confidence stems from cultural self-awareness while cultural self-awareness lies in the recognition of the national culture (idem, pp. 1872-1873)."

Therefore, from the citation, we can safely say that cultural confidence plays a critical role in comparative analysis between Chinese and English.

Yi et al. (2020), Song (2019), Li (2020), Han (2019) and Xu et al. (2019) indicate that the importance of cultural confidence to College students and College English course. Gao et al. (2020) analyzes the roots of cultural confidences from the perspective of high and low context cultures. Shen (2020) studies the relationship between translation and cultural confidence based on Chinese martial arts novels Legends of the Condor Heroes. So, there is need to raise cultural confidence of College students on the comparative perspective of linguistic cultural knowledge between the Eastern and the Western based on those studies.

Under the international background, translation plays a crucial role in the process of cross-cultural communication. Studies show that cultural confidence is a very significant element in College English course and to College students. So, this study wants to explore the effect of linguistic cultural knowledge both including the Eastern and the Western interfering in translation teaching of College English aiming at raising their cultural confidence on their translation competence.

\section{Methodology}

\subsection{Research Questions}

1) What are students' attitudes toward raising their cultural confidence in translation teaching in College English?

2) Will students' translation competence be improved after learning certain linguistic culture knowledge with the purpose of raising their cultural confidence?

\subsection{Participants}

The participants of this study were the freshmen of non-English majors from two classes (the size being 49 and 50 respectively) of Jiangxi University of Engineering, 21 females and 78 males, from 17 to 20 averaging 18.5 years old. They had already studied English 6 to 12 years, averaging 8.2 years.

The two classes were taught by the researcher and randomly assigned as the Controlled Class (CC) and 
Experimental Class (EC). During this experiment, some students didn't join in questionnaire of pre- or post-test or didn't attend the translation of pre- or post-test for some reasons. Only the data collected from the students who had attended the experiment were valid.

\subsection{Instruments}

The instruments applied in the teaching experiment concluded three parts, a questionnaire (both used in pre- and post-test), two translation competence tests (pre- and post-test), and an interview.

First, the questionnaire (seen in Appendix A) was designed with reference to The Application of Peer Review to Translation Teaching of English Majors (Chen, 2013, p. 68). Second, the translation competence tests used in pre- and post-test were from the translation exercises of Unit 1 and Unit 7 in their textbook, New Horizon College English 1. So, the valid and feasibility of two tests were suitable for their translation competence. Third, after the teaching experiment, the researcher randomly selected 10 students for an interview to further know their opinions on introducing the new translation teaching approach.

In the study, Statistical Package of Social Science (SPSS) version 26.0 was employed to analyze the information collected, the scores of participants in the pre- and post-test.

\subsection{Research Procedure}

The whole experiment was conducted from October 27, 2020 to January 7, 2021. During the translation teaching, the $\mathrm{CC}$ was taught by traditional method, mainly the linguistic knowledge, including grammar analysis, sentence structure analysis and words and characters selection, etc. However, the EC, based on traditional translation teaching approach, interfered with linguistic cultural knowledge both including the Eastern and Western aiming to raising their cultural confidence was taught. The research procedure consists of 6 parts.

\subsubsection{Questionnaire (Pre-Test)}

Before pre-test, a questionnaire was applied to know students' attitudes, both those of CC and EC, to the effects of cultural confidence to their translation competence. The questionnaire was carried out on the Wenjuan APP.

\subsubsection{Pre-Test}

Immediately after the questionnaire process, students both in $\mathrm{CC}$ and $\mathrm{EC}$ made the pre-test within 50 minutes to testify their translation competence. In order to ensure the validity of the contents of pre-test and the same level of both pre-test and post-test, and to analyze the data effectively, the researcher choose the translation exercises in their textbook, the Unit 1 as the pre-test.

\subsubsection{Teaching Experiment}

Teaching experiment was lasted one semester, 10 weeks, each translation teaching class with one topic according to the translation exercises of students' textbook. The teacher gave different translation teaching approach to the students of CC and EC, with students from EC being emphasized the related linguistic cultural knowledge about the translation text.

Table 1. Teaching experiment

\begin{tabular}{lll}
\hline Information & Date & Main Idea of the Translation Texts \\
\hline Class I & Nov. 3, 2020 & Character: Socrates Vs. 孔子 (Mencius) \\
Class II & Nov. 17, 2020 & Festival: Christmas Vs. 中秋节 (Mid-Autumn Festival) \\
Class III & Dec. 8, 2020 & Transportation: The London Underground Vs. 中国航天业 (Chinese Space Industry) \\
Class IV & Dec. 15, 2020 & Figure: Marco Polo Vs. 郑和 (Zheng He) \\
Class V & Dec. 29, 2020 & Sports: The origination of the Olympic Games Vs. 太极拳 (Tai Chi) \\
Class VI & Jan. 5, 2021 & Education: Gap year Vs. 中国教育事业 (China's education) \\
\hline
\end{tabular}

In each class, the background information of two text would be introduced. Then, the text would be made comparative analysis sentence by sentence, which was focused on linguistic cultural knowledge. 
Table 2. Comparative analysis

\begin{tabular}{lll}
\hline Original sentence 5 & Linguistic Cultural Analysis 5 & Translation 5 \\
\hline 孔子的很多思想, 尤其是其教育 & $\begin{array}{l}\text { Chinese is a paratactic language with the senses } \\
\text { of the little pearls falling on a plate of jade of big } \\
\text { pearl while English is a hypotactic language with } \\
\text { no }\end{array}$ & $\begin{array}{l}\text { Great amount of Confucius' thought, } \\
\text { especially his thought on education, has } \\
\text { had a profound influence on Chinese } \\
\text { 影响。 }\end{array}$ \\
$\begin{array}{ll}\text { nociate } \\
\text { Socrates was the most colorful } \\
\text { figure in the history of ancient } \\
\text { philosophy. }\end{array}$ & $\begin{array}{l}\text { The rhythmic beauty of Chinese can be reflected } \\
\text { in translating “colorful”into “浓墨重彩”。 }\end{array}$ & $\begin{array}{l}\text { 苏格拉底是古代哲学史上最具浓墨重 } \\
\text { 彩的人物。 }\end{array}$ \\
\hline
\end{tabular}

Table 2 is an excerpt of teaching material of class one. From the comparative analysis in terms of linguistic cultural knowledge, students could enjoy and recognize the feature and beauty of Chinese in a rational way, which could improve their self-cultural confidence and then acquire the confidence and bravery to finish the translation task effectively and proficiently.

\subsubsection{Questionnaire (Post-Test)}

Before post-test, the same questionnaire conducted before pre-test was applied again only to EC students on the Wenjuan APP. The data got in this stage were compared to the data collected in the questionnaire before pre-test in order to compare whether there any changes of students' attitudes towards the new translation teaching approach would be.

\subsubsection{Post-Test}

After the teaching experiment, the post-test was conducted both in CC and EC to testify the students whether their translation competences were improved or not after a semester's translation teaching experiment. Students from both CC and EC finished the post-test within 50 minutes. With the purpose of the guarantee the validity and credibility, the translation exercises of Unit 7 in their textbook were chosen as the post-test because the aspects of structure, difficulty and length both pre- and post-test were the same.

\subsubsection{Interview}

The interview was implemented after the experiment. Ten students were selected randomly from the EC with the purpose of collecting further information about the students' attitudes and getting advice to the new translation teaching approach. Three open-ended questions were designed. The interview was conducted in a classroom only occupied by the researcher and one interviewer at a time and the opinions were recorded for further analysis. The interview could supply some limitations of the questionnaire applied to post-test.

\subsection{Data Collection}

The current study was conducted from October 27, 2020 to January 7, 2021. First, participants did the questionnaire on Wenjuan APP within 5 minutes and the result would be seen from the APP the moment they finished it. Second, the pre-test and post-test were made in their classrooms within 50 minutes. Both the two tests were corrected by the teacher for the sake of the same criterion. Third, the interview was implemented in a quite classroom only occupied by the researcher and one interviewer. After this process, the digital reports would be transcribed into written ones faithfully for further analysis.

\subsection{Data Analysis}

First, the data of questionnaire were made a descriptive analysis. The choice-chosen proportion of each question would be counted. Second, the scores of pre- and post-test were analyzed by SPSS 26.0 to directly compare the translation competence of participants from $\mathrm{CC}$ and $\mathrm{EC}$, which could manifest the effect of the new translation teaching approach on their translation competence. Last, the transcripts of interview recordings would be analyzed as a supplement to the post-test questionnaire.

\section{Results and Discussions}

\subsection{Questionnaire}

The questionnaire was made before and after the teaching experiment. The questionnaire consisted of 2 parts. The first part, five blanks, was about participants' information, including gender, age, major, class and the years for learning English. Then, the first section of part two, question 1 and question 2, were about their attitudes to their cultural confidence. The second section of part two consisting of question 3 to 8 were about their attitudes to their translation competence being effected by raising their cultural confidence through learning linguistic cultural knowledge. The third section of part two containing questions from 9 to 17 were about their attitudes to 
the translation teaching in College English interfered with linguistic cultural knowledge both including the Eastern and Western aiming to raising their cultural confidence. Both the questions of part 2 had 5 options A-E, with A referring to strongly agree and $\mathrm{E}$ referring to strongly disagree.

\subsubsection{Pre-Test Questionnaire}

The results of pre-test questionnaire were shown as Table 3 .

Table 3. Descriptive statistics for questionnaire (pre-test) in CC and EC

\begin{tabular}{lllllll}
\hline QUESTION & $\mathrm{N}$ & $\mathrm{A}$ & $\mathrm{B}$ & $\mathrm{C}$ & $\mathrm{D}$ & $\mathrm{E}$ \\
\hline Question 1 & 95 & $37.9 \%$ & $36.8 \%$ & $21.0 \%$ & $1.0 \%$ & $0 \%$ \\
Question 2 & 95 & $0 \%$ & $1.0 \%$ & $35.8 \%$ & $45.3 \%$ & $17.9 \%$ \\
Question 3 & 95 & $21.1 \%$ & $54.7 \%$ & $24.2 \%$ & $0 \%$ & $0 \%$ \\
Question 4 & 95 & $11.6 \%$ & $54.7 \%$ & $28.4 \%$ & $5.2 \%$ & $0 \%$ \\
Question 5 & 95 & $11.6 \%$ & $44.2 \%$ & $35.8 \%$ & $7.4 \%$ & $1.0 \%$ \\
Question 6 & 95 & $10.5 \%$ & $49.5 \%$ & $32.6 \%$ & $7.4 \%$ & $0 \%$ \\
Question 7 & 95 & $10.5 \%$ & $50.5 \%$ & $25.3 \%$ & $13.7 \%$ & $0 \%$ \\
Question 8 & 95 & $16.8 \%$ & $63.1 \%$ & $14.7 \%$ & $5.3 \%$ & $0 \%$ \\
Question 9 & 95 & $7.4 \%$ & $60.0 \%$ & $26.3 \%$ & $6.3 \%$ & $0 \%$ \\
Question 10 & 95 & $8.4 \%$ & $48.4 \%$ & $34.7 \%$ & $8.4 \%$ & $0 \%$ \\
Question 11 & 95 & $4.2 \%$ & $40 \%$ & $45.3 \%$ & $10.5 \%$ & $0 \%$ \\
Question 12 & 95 & $4.2 \%$ & $40 \%$ & $38.9 \%$ & $14.7 \%$ & $10.5 \%$ \\
Question 13 & 95 & $3.1 \%$ & $44.2 \%$ & $42.1 \%$ & $9.5 \%$ & $1.1 \%$ \\
Question 14 & 95 & $5.3 \%$ & $53.7 \%$ & $28.4 \%$ & $11.6 \%$ & $1.1 \%$ \\
Question 15 & 95 & $6.3 \%$ & $55.8 \%$ & $26.3 \%$ & $10.5 \%$ & $1.1 \%$ \\
Question 16 & 95 & $5.2 \%$ & $44.2 \%$ & $34.7 \%$ & $14.7 \%$ & $1.1 \%$ \\
Question 17 & 95 & $10.5 \%$ & $37.8 \%$ & $45.2 \%$ & $4.2 \%$ & $2.1 \%$ \\
\hline
\end{tabular}

Note. $\mathrm{N}=$ number of participants; option $\mathrm{A}=$ strongly agree; option $\mathrm{B}=$ agree; option $\mathrm{C}=$ uncertainty; option $\mathrm{D}=$ disagree; option $\mathrm{E}=$ strongly disagree.

From the Table 3, In question 1,37.9\% students hold strong cultural confidence to your mother tongue. And in question 2, no students thought that the Western culture is superior to the Eastern culture. Questions from 3 to 8 , over half of the students $(54.7 \%, 54.7 \%, 50.5 \%, 63.1 \%)$ in question 3, 4,7 and 8 agreed and over $10 \%$ of them in all the 6 questions strongly agreed that raising their cultural confidence through learning linguistic cultural knowledge could have positive effects on their translation practices, and Questions from 9 to 17, almost half of the students agreed that the new translation teaching approach in College English could enhance their translation competence.

\subsubsection{Post-Test Questionnaire}

The post-test questionnaire is only conducted to explore whether there is any change of students' attitudes of EC toward new teaching approach with the result of Table 4.

Table 4. Descriptive statistics for questionnaire (post-test) in EC

\begin{tabular}{lllllll}
\hline QUESTION & $\mathrm{N}$ & $\mathrm{A}$ & $\mathrm{B}$ & $\mathrm{C}$ & $\mathrm{D}$ & $\mathrm{E}$ \\
\hline Question 1 & 49 & $53.1 \%$ & $34.7 \%$ & $12.2 \%$ & $0 \%$ & $0 \%$ \\
Question 2 & 49 & $2.0 \%$ & $6.1 \%$ & $32.7 \%$ & $44.9 \%$ & $14.3 \%$ \\
Question 3 & 49 & $44.9 \%$ & $40.8 \%$ & $14.3 \%$ & $0 \%$ & $0 \%$ \\
Question 4 & 49 & $36.7 \%$ & $51.0 \%$ & $12.2 \%$ & $0 \%$ & $0 \%$ \\
Question 5 & 49 & $40.8 \%$ & $38.8 \%$ & $20.4 \%$ & $0 \%$ & $0 \%$ \\
Question 6 & 49 & $38.8 \%$ & $42.9 \%$ & $18.4 \%$ & $0 \%$ & $0 \%$ \\
Question 7 & 49 & $34.7 \%$ & $46.9 \%$ & 16.3 & $2.0 \%$ & $0 \%$ \\
Question 8 & 49 & $36.7 \%$ & $44.9 \%$ & $18.4 \%$ & $0 \%$ & $0 \%$ \\
Question 9 & 49 & $30.6 \%$ & $55.1 \%$ & $14.2 \%$ & $0 \%$ & $0 \%$ \\
Question 10 & 49 & $18.4 \%$ & $57.1 \%$ & $24.5 \%$ & $0 \%$ & $0 \%$ \\
Question 11 & 49 & $20.4 \%$ & $49.0 \%$ & $30.6 \%$ & $0 \%$ & $0 \%$ \\
Question 12 & 49 & $18.4 \%$ & $49.0 \%$ & $32.7 \%$ & $0 \%$ & $0 \%$ \\
Question 13 & 49 & $14.3 \%$ & $55.1 \%$ & $30.6 \%$ & $0 \%$ & $0 \%$ \\
Question 14 & 49 & $2.0 \%$ & $57.1 \%$ & $28.6 \%$ & $0 \%$ & $0 \%$ \\
Question 15 & 49 & $16.3 \%$ & $65.3 \%$ & $16.3 \%$ & $2.0 \%$ & $0 \%$ \\
Question 16 & 49 & $20.4 \%$ & $53.1 \%$ & $22.4 \%$ & $4.1 \%$ & $0 \%$ \\
Question 17 & 49 & $32.7 \%$ & $40.8 \%$ & $24.5 \%$ & $0 \%$ & $2.0 \%$ \\
\hline
\end{tabular}

Note. $\mathrm{N}=$ number of participants; option $\mathrm{A}=$ strongly agree; option $\mathrm{B}=$ agree; option $\mathrm{C}=$ uncertainty; option $\mathrm{D}=$ disagree; option $\mathrm{E}=$ strongly disagree. 
After a semester's new teaching approach, the data collected from the post-questionnaire showed that the proportion of A and B chosen of all questions is increased, which reflected that students' attitudes of EC toward new teaching approach were more positive than before. However, in question 2-"In College English, you think the Western culture is superior to the Eastern culture."-it is noted that the proportion of option A and option B is increased and that of option C, D and E is decreased. It cannot be denied that the question 2 is too subjective to make a rational choice and designation of the questionnaire has its limitation. But the data collected from the questionnaire, to some extent, reflected that the shortage of linguistic cultural knowledge in College English of non-English majors made them confused and puzzled about the cultural knowledge during their study process, especially the translation.

\subsection{Pre-Test and Post-Test}

\subsubsection{Pre-Test Study}

Table 5. Descriptive statistics for pre-test between EC and CC

\begin{tabular}{lllllll}
\hline Group & Number & Minimum & Maximum & Mean & Std. Deviation & Sig. \\
\hline EC & 49 & 0 & 88 & 39.56 & 22.627 & .843 \\
CC & 49 & 0 & 89 & 38.69 & 20.496 & \\
\hline
\end{tabular}

Note. $\mathrm{EC}=$ Experimental Class; $\mathrm{CC}=$ Controlled Class.

Table 6. The frequency distribution of scores in the pre-test between EC and CC

\begin{tabular}{lllll}
\hline \multirow{2}{*}{ Marks } & Frequency & \multicolumn{3}{l}{ Percentage } \\
\cline { 2 - 5 } & EC & CC & EC & CC \\
\hline Above 80 & 1 & 1 & $2 \%$ & $2 \%$ \\
$70-79$ & 3 & 2 & $6.2 \%$ & $4.1 \%$ \\
$60-69$ & 5 & 5 & $10.2 \%$ & $10.2 \%$ \\
$50-59$ & 8 & 7 & $16.3 \%$ & $14.3 \%$ \\
Below 50 & 32 & 34 & $65.3 \%$ & $69.4 \%$ \\
Total & 49 & 49 & $100 \%$ & $100 \%$ \\
\hline
\end{tabular}

Note. $\mathrm{EC}=$ Experimental Class; $\mathrm{CC}=$ Controlled Class.

Table 7. Independent samples $\mathrm{T}$ for the mean scores of the two classes in the pre-test

\begin{tabular}{llllll}
\hline Group Statistics & & & & \\
\hline Pre-test & Class & Number & Mean & Std. Deviation & Std. Error Mean \\
\cline { 2 - 6 } & EC & 49 & 39.56 & 22.627 & 3.232 \\
& CC & 49 & 38.69 & 20.496 & 2.928 \\
\hline
\end{tabular}

Note. $\mathrm{EC}=$ Experimental Class $; \mathrm{CC}=$ Controlled Class.

\begin{tabular}{|c|c|c|c|c|c|c|c|c|c|c|}
\hline \multicolumn{11}{|c|}{ Independent Sample test } \\
\hline & & \multirow{2}{*}{\multicolumn{2}{|c|}{$\begin{array}{l}\text { Levene's Test for } \\
\text { Equality of Variances }\end{array}$}} & \multirow{2}{*}{\multicolumn{7}{|c|}{ t-test for Equality of Means }} \\
\hline & & & & & & & & & & \\
\hline & & \multirow[t]{2}{*}{$\overline{\mathrm{F}}$} & \multirow[t]{2}{*}{ Sig. } & \multirow[t]{2}{*}{$\mathrm{t}$} & \multirow[t]{2}{*}{$\mathrm{df}$} & \multirow[t]{2}{*}{$\begin{array}{l}\text { Sig. } \\
\text { (2-tailed) }\end{array}$} & \multirow[t]{2}{*}{$\begin{array}{l}\text { Mean } \\
\text { Difference }\end{array}$} & \multirow[t]{2}{*}{$\begin{array}{l}\text { Std. Error } \\
\text { Difference }\end{array}$} & \multicolumn{2}{|c|}{$\begin{array}{l}95 \% \text { Confidence Interva } \\
\text { of the difference }\end{array}$} \\
\hline & & & & & & & & & Lower & Upper \\
\hline \multirow[t]{2}{*}{ Pre-test } & $\begin{array}{l}\text { Equal Variance } \\
\text { assumed }\end{array}$ & .399 & .529 & .199 & 96 & .843 & .867 & 4.361 & -7.790 & 9.525 \\
\hline & $\begin{array}{l}\text { Equal Variance } \\
\text { not assumed }\end{array}$ & & & .199 & 95.076 & .843 & .867 & 4.361 & -7.791 & 9.526 \\
\hline
\end{tabular}

Note. $\mathrm{EC}=$ Experimental Class; $\mathrm{CC}=$ Controlled Class.

Before the teaching experiment was conducted, a pre-test was carried out between EC and CC. As Table 5 shows, especially the significant difference between the scores of EC and CC is 0.843 which is quite higher than 0.05 , it can be safely concluded that, before the experiment, there is no significant difference in students' translation competence between the two classes.

Through Table 6, the frequency distribution of the scores reflects that the general translation competence 
between the two class is the same before the teaching experiment.

In Table 7, the Independent Sample $\mathrm{T}$ test is implemented to further analyze the scores of the pre-test. The significant difference (Sig.) is 0.529 which is highly over 0.05 and the 2-tailed Sig. is 0.843 which is also over 0.05 , both showing that the variances of the pre-test scores between EC and CC are equal. The Std. Error Difference is only 4.361 indicates that there exist no significant differences between the two classes. According to the Group Statistics in Table 6, we can see that the difference of standard deviations between EC and CC is slight, EC 22.627 and CC 20.496, which is rational. As a result of that, there is no doubt that the scores between the two classes have a same dispersion.

From the three aspects mentioned above, we can make a safe conclusion that the translation competences of students in EC and CC are located in the same level before the experiment. And the validity and credibility of the research can be assured.

\subsubsection{Post-Test Study}

Being introduced different translation teaching approaches between $\mathrm{EC}$ and $\mathrm{CC}$, there appears some changes in students' translation competences between EC and CC.

Table 8. Descriptive statistics for post-test between EC and CC

\begin{tabular}{llllll}
\hline Group & Number & Minimum & Maximum & Mean & Std. Deviation \\
\hline EC & 49 & 19 & 91 & 55.79 & 18.970 \\
CC & 49 & 0 & 82 & 38.90 & 19.271 \\
\hline
\end{tabular}

Note. $\mathrm{EC}=$ Experimental Class; $\mathrm{CC}=$ Controlled Class.

Table 9. The frequency distribution of scores in the post-test between EC and CC

\begin{tabular}{lllll}
\hline \multirow{2}{*}{ Marks } & Frequency & \multicolumn{3}{l}{ Percentage } \\
\cline { 2 - 5 } & EC & CC & EC & CC \\
\hline Above 80 & 6 & 2 & $12.2 \%$ & $4.1 \%$ \\
$70-79$ & 7 & 0 & $14.3 \%$ & $0 \%$ \\
$60-69$ & 9 & 6 & $18.4 \%$ & $12.2 \%$ \\
$50-59$ & 9 & 9 & $18.4 \%$ & $18.4 \%$ \\
Below 50 & 18 & 32 & $36.7 \%$ & $65.3 \%$ \\
Total & 49 & 49 & $100 \%$ & $100 \%$ \\
\hline
\end{tabular}

Note. $\mathrm{EC}=$ Experimental Class; $\mathrm{CC}=$ Controlled Class.

Table 10. Independent samples $\mathrm{T}$ for the mean scores of the two classes in the pre-test

\begin{tabular}{llllll}
\hline Group Statistics & & & & \\
\hline Post-test & Class & Number & Mean & Std. Deviation & Std. Error Mean \\
\cline { 2 - 6 } & EC & 49 & 55.79 & 18.970 & 2.710 \\
& CC & 49 & 38.90 & 19.271 & 2.753 \\
\hline
\end{tabular}

Note. $\mathrm{EC}=$ Experimental Class; $\mathrm{CC}=$ Controlled Class.

\begin{tabular}{|c|c|c|c|c|c|c|c|c|c|c|}
\hline \multicolumn{11}{|c|}{ Independent Sample test } \\
\hline & & \multirow{2}{*}{\multicolumn{2}{|c|}{$\begin{array}{l}\text { Levene's Test for } \\
\text { Equality of Variances }\end{array}$}} & \multirow{2}{*}{\multicolumn{7}{|c|}{ t-test for Equality of Means }} \\
\hline & & & & & & & & & & \\
\hline & & \multirow[t]{2}{*}{$\mathrm{F}$} & \multirow[t]{2}{*}{ Sig. } & \multirow[t]{2}{*}{$\mathrm{t}$} & \multirow[t]{2}{*}{$\mathrm{df}$} & \multirow[t]{2}{*}{$\begin{array}{l}\text { Sig. } \\
\text { (2-tailed) }\end{array}$} & \multirow[t]{2}{*}{$\begin{array}{l}\text { Mean } \\
\text { Difference }\end{array}$} & \multirow[t]{2}{*}{$\begin{array}{l}\text { Std. Error } \\
\text { Difference }\end{array}$} & \multicolumn{2}{|c|}{$\begin{array}{l}95 \% \text { Confidence Interva } \\
\text { of the difference }\end{array}$} \\
\hline & & & & & & & & & Lower & Upper \\
\hline \multirow[t]{2}{*}{ Post-test } & $\begin{array}{l}\text { Equal Variance } \\
\text { assumed }\end{array}$ & .003 & .957 & 4.372 & 96 & .000 & 16.888 & 3.863 & 9.220 & 24.556 \\
\hline & $\begin{array}{l}\text { Equal Variance } \\
\text { not assumed }\end{array}$ & & & 4.372 & 95.976 & .000 & 16.888 & 3.863 & 9.220 & 24.556 \\
\hline
\end{tabular}

Note. $\mathrm{EC}=$ Experimental Class; $\mathrm{CC}=$ Controlled Class. 
When the teaching experiment was finished, a post-test was carried out between EC and CC. As Table 8 shows that, after the experiment, the performances of students in EC are better than those of in $\mathrm{CC}$ in an all-around way.

Through Table 9, the frequency distribution of the scores of post-test between EC and CC can be seen, which reflects that, in $\mathrm{CE}$, the general translation competence between the two class has been changed sharply after the teaching experiment.

In Table 10, the Independent Sample $\mathrm{T}$ test is made to further analyze the scores of the post-test. The significant probability of F is 0.003 which is lower than 0.05 and the 2-tailed Sig. is well lower than 0.05 , both showing that there is significant difference between students' translation competence in EC and CC. Moreover, the significant difference of post-test scores between EC and CC showed by Independent Sample test is 0.957, well higher than 0.05 , all of which tells that there exists great difference between the post-test scores of students in EC and CC.

Before the teaching experiment, the results of pre-test scores of EC and CC analyzed by SPSS shows that the students' translation competence between EC and CC were relatively the same. However, after a semester's teaching experiment, the data of post-test scores analyzed by the SPSS tells the translation competence of students from EC have been improved greatly which can be attributed to the new teaching approach, translation teaching class interfered with linguistic cultural knowledge both including the Eastern and Western aiming to raising your cultural confidence. As a result from that, we can say that through the application of translation teaching classes interfered with linguistic cultural knowledge both including the Eastern and Western aiming to raising your cultural confidence, students' translation competence improved sufficiently.

\subsubsection{Comparison of EC's Scores in the Pre-Test and Post-Test}

Table 11. Paired samples T test for the mean scores in EC

\begin{tabular}{lllllll}
\hline \multicolumn{2}{l}{ Paired Samples Statistics } \\
\hline Pair 1 & Mean & Number & Std. Deviation & Correlation & Sig. \\
\cline { 2 - 7 } & Pre-test & 39.56 & 49 & 22.627 & .988 & .000 \\
& Post-test & 55.79 & 49 & 18.970 & & \\
\hline
\end{tabular}

\begin{tabular}{|c|c|c|c|c|c|c|c|c|c|}
\hline \multicolumn{10}{|c|}{ Paired Samples Test } \\
\hline & & \multicolumn{5}{|c|}{ Paired Differences } & \multirow{3}{*}{$-{ }^{t}$} & \multirow[t]{3}{*}{ df } & \multirow[t]{3}{*}{ Sig. (2-tailed) } \\
\hline & & \multirow[t]{2}{*}{ Mean } & \multirow[t]{2}{*}{$\begin{array}{l}\text { Std. } \\
\text { Deviation }\end{array}$} & \multirow[t]{2}{*}{$\begin{array}{l}\text { Std. Error } \\
\text { Mean }\end{array}$} & \multicolumn{2}{|c|}{$\begin{array}{l}95 \% \text { Confidence Interval of } \\
\text { the Difference }\end{array}$} & & & \\
\hline & & & & & Lower & Upper & & & \\
\hline Pair 1 & $\begin{array}{l}\text { Pre-test - } \\
\text { Post-test }\end{array}$ & -16.224 & 4.855 & .694 & -17.619 & -14.830 & -23.391 & 48 & .000 \\
\hline
\end{tabular}

From the Paired Samples Correlation in Table 11, the correlation of pre- and post-test of EC is 0.988 and the Sig. is 0 , which shows that the scores of pre- and post-test of EC are significantly related. Then, the Paired Samples Test shows that the $t$ value is -23.391 and the Sig. is lower than 0.05 which reflects that there exists significantly difference between the scores of pre-test and post-test of EC.

Consequently, from the analysis mentioned above, after a semester' new teaching approach, the translation competences of EC have been improved greatly and efficiently.

4.2.4 Comparison of CC's Scores in the Pre-Test and Post-Test

Table 12. Paired samples $\mathrm{T}$ test for the mean scores in $\mathrm{CC}$

\begin{tabular}{|c|c|c|c|c|c|c|}
\hline \multirow[t]{3}{*}{ Pair 1} & & Mean & Number & Std. Deviation & Correlation & Sig. \\
\hline & Pre-test & 38.69 & 49 & 20.496 & .990 & .000 \\
\hline & Post-test & 38.90 & 49 & 19.271 & & \\
\hline
\end{tabular}




\begin{tabular}{|c|c|c|c|c|c|c|c|c|c|}
\hline \multicolumn{10}{|c|}{ Paired Samples Test } \\
\hline & & \multicolumn{5}{|c|}{ Paired Differences } & \multirow{3}{*}{$\bar{f}^{\mathrm{t}}$} & \multirow[t]{3}{*}{$\mathrm{df}$} & \multirow[t]{3}{*}{ Sig. (2-tailed) } \\
\hline & & \multirow[t]{2}{*}{ Mean } & \multirow[t]{2}{*}{$\begin{array}{l}\text { Std. } \\
\text { Deviation }\end{array}$} & \multirow[t]{2}{*}{$\begin{array}{l}\text { Std. Error } \\
\text { Mean }\end{array}$} & \multicolumn{2}{|c|}{$\begin{array}{l}95 \% \text { Confidence Interval of } \\
\text { the Difference }\end{array}$} & & & \\
\hline & & & & & Lower & Upper & & & \\
\hline Pair 1 & $\begin{array}{l}\text { Pre-test - } \\
\text { Post-test }\end{array}$ & -.204 & 3.034 & .433 & -1.076 & .667 & -.471 & 48 & .640 \\
\hline
\end{tabular}

Through Table 12, the mean scores of pre-test and post-test of CC in Paired Samples Statistics are almost the same. What's more, from the Paired Samples Correlation in Table 12, the correlation of pre-test and post-test of $\mathrm{CC}$ is 0.990 and the Sig. is 0 , showing that the scores of pre-test and post-test of CC are significantly related. Then, the Paired Samples Test shows the Sig. is 0.640 which is well over 0.05 which reflects that there exists no significantly difference between the scores of pre-test and post-test of CC.

Consequently, from the analysis mentioned above, after a semester' traditional teaching method, the gap of students' translation competences in $\mathrm{CC}$ is light and not evident.

\subsection{Interview}

After the post-test, 10 students were selected randomly from the EC to answer the following three questions in the interview:

1) Do you like to interfere with linguistic cultural knowledge both including the Eastern and Western aiming to raising your cultural confidence in our translation teaching classes? Why or why not?

2) Do you think that your translation has been enhanced through the semester being interfered with linguistic cultural knowledge both including the Eastern and Western aiming to raising your cultural confidence in our translation teaching classes? If so, what kind of aspect(s) has(have) been enhanced?

3) What suggestions could you propose to our translation teaching classes interfered with linguistic cultural knowledge both including the Eastern and Western aiming to raising your cultural confidence in the future?

\subsubsection{Question One}

In their responses to the question one, we can see that almost all the interviewers like translation teaching classes interfered with linguistic cultural knowledge both including the Eastern and Western aiming to raising your cultural confidence. Moreover, they thought that learned some linguistic cultural knowledge will let them cultivated a motivation to learn and study deeper knowledge about the language based on the linguistic cultural knowledge and to analyze the differences between Chinese and English embodied in superficial language phenomenon. Several responses to the question one are demonstrated in the following:

"I like to think about language. Because after language learning for many years, I find that my mother tongue, Chinese, is beautiful. But the Chinese characters are different from English words, for the meanings of characters are different under different circumstances. When I read a character I don't understand, I will seek what is the real meaning of it. So, I am able to make a proficient translation."

"I think it (translation teaching classes interfered with linguistic cultural knowledge both including the Eastern and Western aiming to raising your cultural confidence) is OK. Because something like language discrepancy is difficult to understand, you have to study it. Em...during doing translation, both including English to Chinese translation and Chinese to English translation, you cannot just translate the language literally. But, only after understanding the cultural information, can a better translation be made. Because the translation process has close relationship with linguistic cultural knowledge."

"I like the translation teaching class in this semester. Because after this semester's learning, I feel that not only can the cultural confidence of my country be improved, but also have a deep and reasonable understanding about (the difference of) Chinese and English. So, I can know how to translate as well as linguistic knowledge."

"I like to learn linguistic cultural knowledge. Because I am interested in the Western culture, so I want to lean more about it. And, furthermore, I will think about what is the difference between the Western culture and my country's culture (Chinese culture). As a result of it, I can understand English more reasonable."

"I like translation teaching classes interfered with linguistic cultural knowledge both including the Eastern and Western aiming to raising your cultural confidence. Because after establish the cultural confidence, you have more motivations to learn the Chinese and English) language." 


\subsubsection{Question Two}

In their responses to question two, most of the interviewers admitted that translation teaching classes interfered with linguistic cultural knowledge both including the Eastern and Western aiming to raising your cultural confidence could improve their translation competence in some extent. Several responses to the question two are demonstrated in the following:

"I think that my translation competence has been improved through learning linguistic cultural knowledge aiming to raising my cultural confidence. After this semester's learning, I can make a better understanding about the deep structure of Chinese and English during translating, I want to find the reason why I should translate the language like that, and I want to know more about translation. Translation is beautiful."

"I think my translation competence has been improved a little bit through learning linguistic cultural knowledge aiming to raising my cultural confidence. Because interesting, I think is the most important matter when studying. By raising cultural confidence, I notice that, wow, China (Chinese culture) is so great. There still has so many things to be learned. And then you are more interested in it. So you want to learn and study more."

"I think my translation competence has been improved a little. Because I will strengthen the confidence to my mother tongue by raising cultural confidence. And I will know more about culture, which will broaden my horizon. And I will have more courage to make the translation better by considering the logic difference between Chinese and English. My logic thinking has been improved."

"It (Linguistic cultural knowledge aiming to raising my cultural confidence) is beneficial to translation competence improvement. Especially speaking, my linguistic logic thinking has been improved. Because the linguistic logic of Chinese and that of English are different."

"It is absolutely that my translation competence has been improved, especially on the aspects of the smoothness and coherence of language. After learning the linguistic cultural knowledge, I have a rational understanding about the differences between Chinese and English. And, then my cultural confidence established and raised, I can express the language and myself better."

\subsubsection{Question Three}

In their responses to question three, most of the interviewers put forward lots of useful suggestions about the improvement of translation teaching interfered with linguistic cultural knowledge aiming to raising cultural confidence. Several responses to the question three are demonstrated in the following:

"Practice more. Before this semester's learning, I just thought that it was useless to practice translation. At the beginning of learning English, I thought it was difficult to learn and meaningless. But now, I can not only translate a text, but also recognize, know and understand the language through learning the linguistic cultural knowledge. And I become confident on my mother tongue."

"I hope that in translation teaching class, more examples relating to the linguistic cultural knowledge can be taken."

"I hope the analysis about the linguistic cultural knowledge could be analyzed more elaborately and clearly."

However, there exists some opposite opinions about the new teaching approach, which are illustrated in aspects like:

"I don't think translation teaching class interfered with linguistic cultural knowledge aiming to raising cultural confidence can improve my translation competence."

"I think the effects of linguistic cultural knowledge aiming to raising cultural confidence can improve my translation competence are not so great."

To sum up, there was still room for the improvement of translation teaching interfered with linguistic cultural knowledge aiming to raising cultural confidence which could be shown in the two opposite suggestions mentioned above. However, most students held positive opinions about the teaching approach of this kind. They acknowledged that this new teaching way was effective or not only if their improvements in translation competence should be made for better results. 


\section{Conclusion}

\subsection{Major Findings}

On the basis of results and discussion, we can summarize the major findings of the current research on the two aspects:

Firstly, it manifests that students keep a positive attitude toward raising their cultural confidence through linguistic cultural knowledge learning in translation teaching in College English. Their attitudes are embodied in the two questionnaires and the interview after post-test. The majority of them admit that they like this new teaching approach.

Secondly, students' translation competence is improved after learning linguistic culture knowledge with the purpose of raising their cultural confidence. It is undeniable that the translation competence of students in EC is well better than that of students in CC.

To sum up, from empirical study and theoretical review, raising non-English majors' cultural confidence through linguistic cultural knowledge learning in translation teaching in College English has a positive influence on their translation competence. Thus, the application of cultural confidence to translation teaching in College English is an available way.

\subsection{Implications}

Two implications have been worked out from the findings of this current study.

Theoretically, the improvement of translation studies about how to combine the Eastern and Western culture in translation teaching with the aim of raising self-cultural confidence should be further made. "Cultural confidence is the base and main driving force for carrying forward China's excellent traditional culture... Cultivating and enhancing college students' cultural confidence in the new era is not only a necessary demand for national cultural development, but also reflects the requirements of The Times for ideological and political education" (Xu, et al., 2019, p. 131). Translation is a process concerning to the transformation of from source language to target language (here refers to Chinese and English). But, actually, the process is not so simple only concerning with the superficial language. The purpose of translation is translating the culture but not the language (Casagrande, 1954, p. 338). Lan made the explanation about the opinion: 1) the two languages themselves involved in translation are the production of social culture; 2) there must be cultural elements affecting the motivation and influences of translation process; 3 ) the difficulties of translation are not only situated on the difference between two languages but on the discrepancies between two cultures (Lan, 2019, p. 10). Therefore, nowadays, comparative cultural analysis should turn into the vital part of translation studies but not bilingual sub-competence, knowledge about translation, instrumental sub-competence, strategic and psycho-physiological competence in College English field of translation studies.

Pedagogically, as to non-English majors, it is beneficial to raise their self-cultural confidence in translation teaching of CE. Especially speaking, when having a rational recognition about the difference between linguistic cultural knowledge of Chinese and that of English, by raising and establishing the cultural confidence, students have the bravery to convey the information of source language into the formation of target language. "It is an incontrovertible fact that, throughout history, translation has always helped facilitate intercultural communication... Translation has been of paramount importance in the interaction between cultures" (Shehab et al., 2020, p. 126). Chinese students are taught the English grammatical skills and knowledge from the beginning of their English learning so they are good at English analysis. However, linguistic cultural knowledge of Chinese is overlooked and linguistic cultural knowledge between the Eastern and the Western is ignored in CE. So, if translation teaching in $\mathrm{CE}$ can be paid more attention to Chinese cultural linguistic knowledge and the comparative analysis between the discrepancies of Chinese and English, interesting in learning English of non-English undergraduates and their translation competence will be enhanced.

\subsection{Limitations}

Although this empirical research process has been carefully designed and implemented, it is still with its limitations.

First, it is time limitation. The teaching experiment only lasted one semester, 10 weeks in total. The research result will be more valid if the experiment can be conducted two semesters, or even four semesters.

Second, it is size limitation. There are only 98 students from the same university participated in the teaching experiment. So the conclusion is not suitable for a large size group. And those students are major in science and engineering, so the gender proportion is also a limitation. If the teaching experiment can be conducted in a large 
sample size, the influence of gender matter aspect may be decreased.

Third, the linguistic cultural knowledge is so abstract that it cannot be made a principal comparison between two languages (here refers to Chinese and English), especially when those two languages belong to two different language family. So, if researchers really want to raise Chinese students' cultural confidence through introducing linguistic cultural knowledge in translation teaching in College English in China, there still more and profound study about this field, especially Chinese linguistic area, should be made.

\section{Acknowledgments}

I appreciate the three sophomores giving us a favor to transcribe the recordings of the interview.

\section{References}

Askari, M. I., \& Nikoopour, J. (2018). The Impact of Teaching Methods Applied in Translation Courses on the Translation Proficiency Development of Student Majoring in English Language. Journal of Language and Translation, 8(1), 65-83.

Casagrande, J. B. (1954). The Ends of Translation. International Journal of American Linguistics, 20, 335-340. https://doi.org/10.1086/464296

Chen, F. L. (2013). The Application of Peer Review to Translation Teaching of English Majors. Shandong Normal University.

Cu, Y. L., \& Yan, W. Z. (2008). Research on Status and Strategy of Chinese Linguistic Competence of Undergraduates. Journal of Inner Mongolia Agricultural University (Social Science Edition), 10(37), $227-228$.

Gao, Y. M., \& Wang, Y. (2020). Analysis the Roots of Cultural Confidences from the Perspective of High and Low Context Cultures-A Case study of Burberry's Advertisement. Advances in Social Science, Education and Humanities Research, 445, 143-147.

Han, C. C. (2019). New Media: Cultural Confidence and Core Values Education in Colleges and Universities. Advances in Social Science, Education and Humanities Research, 378, 157-160.

Huang, X. H. (2020). Research on Existing Problems and Countermeasures in College English Translation teaching. Review of Educational Theory, 3(3), 10-13. https://doi.org/10.30564/ret.v3i3.1930

Huang, Z. D. (1997). Translation Competence and Translation Education. Shanghai Journal of Translators for Science and Technology, 3, 26-31.

Lan, H. J. (2019). On Research Methodology in Translation Studies.

Li, X. J. (2020). A Study on the Specific Approaches to the Integration of Red Cultural Resources into College Students' Cultural Confidence. Advances in Social Science, Education and Humanities Research, 433, 201-205.

Lu, J. (2019). Cultivation of "Cultural Confidence" in Foreign Literature Course from a Comparative Perspective. Universal Journal of Educational Research, 7(9), 1869-1873. https://doi.org/10.13189/ujer.2019.070904

Miao, J. (2006). Translation Competence Research - the Basis of Translation Teaching Model Construction. Foreign Language and Their Teaching, 4, 47-50.

Mu, L. (2006). Translation Competence and Translation Testing. Shanghai Journal of Translators, 2, 43-47.

PATCE GROUP. (2009). Results of the Validation of the PACTE Translation Competence Model: Acceptability and decision making. Across Languages and Cultures, 10(2), 207-230. https://doi.org/10.1556/Acr.10.2009.2.3

Shehab, E., \& Thawabteh, M. A. (2020). Undergraduate translation teaching: A pedagogical perspective. Journal of Linguistics, Philology and Translation, 50, 124-148. https://doi.org/10.7764/onomazein.50.04

Shen, Y. Q. (2021). On the Translation of Xia Culture in Chinese Martial Arts Novels under the Background of Cultural Confidence based on Legends of the Condor Heroes. International Journal of English Literature and Social Sciences, 6(1), 33-40. https://doi.org/10.22161/ijels.61.4

Siregar, R., Risnawaty, A. Y., \& Sembiring, M. (2020). Reflection of Undergraduate Students on Translation Process: An Outlook of Translation Teaching in University. Lingua Cultura, 14(4), 57-67. https://doi.org/10.21512/lc.v14i1.6232

Song, C. S. (2019). Study on Countermeasures to Improve the Cultural Confidence of Young College Students. 
Open Journal of Social Sciences, 7, 347-351. https://doi.org/10.4236/jss.2019.712026

Tong, Y. H. (2010). PACTE Translation Competence Model Research. Journal of PLA University of Foreign Languages, 33(5), 88-92.

Tu, G. P. (2009). Research on Status and Strategy of Chinese Written Competence of Undergraduates. China University Teaching, 12, 76-79.

Tu, G. P. (2010). Research on Status and Strategy of Chinese Written Competence of Secondary Students. Modern Chinese, 127-129.

Wang, J. P., Zhao, R., Ju, N. N., \& Yu, Y. (2020). Translation Competence Development: The Focus in Translation Teaching. Advances in Social Science, Education and Humanities Research, 490, 212-216.

Xu, C. M., Wang, C., \& Yang, N. (2019). A study on the improvement of college students' cultural confidence from the perspective of ideological and political education. Advances in Economics, Business and Management Research, 116, 130-134.

Yi, Y., \& Dan, W. (2020). The Realization of Ideological and Political Education in College English Based on Cultural Confidence. Creative Education, 11, 2193-2198. https://doi.org/10.4236/ce.2020.1111158

Zou, Y. Q. (2016). Impact of Chinese Grammatical Knowledge on Translation on Think-Aloud Protocols. English Language and Literature Studies, 6(3), 47-58. https://doi.org/10.5539/ells.v6n3p47

\section{Appendix A}

\section{Questionnaire}

[Personal information]

Gender: Age: Class: Major: Time (years) for learning English:

Please choose the best option according to your own condition.

1. You hold strong cultural confidence to your mother tongue. ( )
A. Strongly agree
B. Agree
C. Uncertainty
D. Disagree E. Strongly disagree

2. In College English, you think the Western culture is superior to the Eastern culture. ( )
A. Strongly agree
B. Agree
C. Uncertainty
D. Disagree E. Strongly disagree

3. Establishing cultural confidence is beneficial to ability of linguistic awareness and competence. ( )
A. Strongly agree
B. Agree
C. Uncertainty
D. Disagree E. Strongly disagree

4. Establishing cultural confidence is beneficial to the content and structure of the text. ( )
A. Strongly agree
B. Agree
C. Uncertainty
D. Disagree E. Strongly disagree

5. Establishing cultural confidence is beneficial to Chinese to English translation process. ( )
A. Strongly agree
B. Agree
C. Uncertainty
D. Disagree
E. Strongly disagree

6. Establishing cultural confidence is beneficial to English to Chinese translation process. ( )
A. Strongly agree
B. Agree
C. Uncertainty
D. Disagree
E. Strongly disagree

7. Establishing cultural confidence is beneficial to the sentence structure, grammar and words selection during translation process. ( )
A. Strongly agree
B. Agree
C. Uncertainty
D. Disagree
E. Strongly disagree

8. When making translation, you will think about the differences of linguistic cultural knowledge between Chinese and English. ( )
A. Strongly agree
B. Agree
C. Uncertainty
D. Disagree
E. Strongly disagree

9. In College English, you like the translation teaching interfered with linguistic cultural knowledge. ( )
A. Strongly agree
B. Agree
C. Uncertainty
D. Disagree
E. Strongly disagree

10. After learning the linguistics cultural knowledge aiming at raising cultural confidence, the ability of linguistic awareness and competence is improved. ( )
A. Strongly agree
B. Agree
C. Uncertainty
D. Disagree
E. Strongly disagree 
11. After learning the linguistics cultural knowledge aiming at raising cultural confidence, the quality of translation is improved. ( )
A. Strongly agree
B. Agree
C. Uncertainty
D. Disagree
E. Strongly disagree

12. After learning the linguistics cultural knowledge aiming at raising cultural confidence, the sentence structure translated by you is more concise and authentic. ( )
A. Strongly agree
B. Agree
C. Uncertainty
D. Disagree
E. Strongly disagree

13. After learning the linguistics cultural knowledge aiming at raising cultural confidence, the target language on the aspects of syntax, grammar and words translated by you is improved. ( )
A. Strongly agree
B. Agree
C. Uncertainty
D. Disagree
E. Strongly disagree

14. After learning the linguistics cultural knowledge aiming at raising cultural confidence, you can better understand the source text. ( )
A. Strongly agree
B. Agree
C. Uncertainty
D. Disagree
E. Strongly disagree

15. After learning the linguistics cultural knowledge aiming at raising cultural confidence, you can express the target language better. ( )
A. Strongly agree
B. Agree
C. Uncertainty
D. Disagree
E. Strongly disagree

16. After learning the linguistics cultural knowledge aiming at raising cultural confidence, your interesting in translation is increased. ( )
A. Strongly agree
B. Agree
C. Uncertainty
D. Disagree
E. Strongly disagree

17. After learning the linguistics cultural knowledge aiming at raising cultural confidence, you are more fond of translation teaching in College English then before. ( )
A. Strongly agree
B. Agree
C. Uncertainty
D. Disagree
E. Strongly disagree

\section{Copyrights}

Copyright for this article is retained by the author, with first publication rights granted to the journal.

This is an open-access article distributed under the terms and conditions of the Creative Commons Attribution license (http://creativecommons.org/licenses/by/4.0/). 